\title{
Hacia una mirada dialéctica del patrimonio
}

\author{
Towards a dialecticalview of heritage
}

\author{
Nahir Meline Cantar nahir.cantar@gmail.com \\ http://orcid.org/0000-0003-2610-5591 \\ Instituto del Hábitat y del Ambiente; Facultad de Arquitectura, \\ Urbanismo y Diseño; Universidad Nacional de Mar del Plata (Argentina)
}

\section{Resumen}

El patrimonio cultural es una construcción social compleja en la cual los procesos de patrimonialización exponen a los bienes culturales a lo público. A partir de esta concepción, en este trabajo se presentan una serie de reflexiones sobre lo público del patrimonio cultural y los procesos de patrimonialización desde una perspectiva histórico-dialéctica. En este sentido, este artículo indaga sobre las negatividades que generan los diferentes actores involucrados en los procesos de apropiación del patrimonio, para luego explorar sobre la territorialización del 
patrimonio en el espacio público y su importancia en el derecho a la ciudad. A través de este recorrido se intentará entender los conflictos en términos de poder, legitimidad e intereses que recaen sobre el patrimonio y la importancia que este tiene en los procesos de apropiación del espacio urbano.

Palabras clave: Patrimonio cultural; ámbito público; actores; negatividad.

\begin{abstract}
Cultural heritageis a complex social construction in which patrimonialization processes expose cultural as sets in the public sphere. From this conception, this paper presents a series of reflections on the public aspect of cultural heritage and patrimonialization processes from a historical-dialectical perspective. In this sense, this article explores the negativities generated by the different actors involved in the heritage appropriation processes, to then explore the territorialization of heritage in the public space and its importance from the point of view of the right to the city. Through this analysis, itisaimed tounderstand the conflicts in terms of power, legitimacy and interests that fall on the heritage and the importance that this has in the processes of appropriation of the urban space.
\end{abstract}

Keywords: Cultural heritage; public sphere; actors; negativity.

Se ha señalado que el patrimonio cultural está constituido por "aquellos bienes tangibles o intangibles que una comunidad, o al menos determinados sectores de ella, eligen proteger como testimonio del pasado y desean transmitir a generaciones venideras" (Endere, 2009: 29). Estos bienes comprenden

las obras de sus artistas, arquitectos, músicos, escritores y sabios, así como las creaciones anónimas, surgidas del alma popular, y el conjunto de valores que dan sentido a la vida, es decir, las obras materiales y no materiales que expresan la creatividad de ese pueblo; la lengua, los ritos, las creencias, los lugares y monumentos históricos, la literatura, las obras de arte y los archivos y bibliotecas (UNESCO, 1982). 
Paralelamente, el patrimonio natural ha sido definido como aquellos monumentos naturales compuestos por formaciones físicas y biológicas, formaciones geológicas y fisiográficas que constituyan el hábitat de especies, animal y vegetal, amenazadas y lugares naturales o las zonas naturales estrictamente delimitadas, que tengan un valor universal excepcional desde el punto de vista de la ciencia, de la conservación o de la belleza natural (UNESCO, 1972).

Acorde a estas definiciones se puede afirmar que el patrimonio cultural se manifiesta sólo en el ámbito de lo público, en tanto el mismo se construye desde la colectividad y no desde la individualidad, característica necesaria para hablar de ámbitos privados. Cabe aclarar que no se entiende aquí "lo público" en términos de dominio sino en relación al interés que la cuestión reviste para el colectivo social. En este sentido se ha manifestado que los procesos de patrimonialización convierten "la herencia cultural de cada uno, (en) el patrimonio cultural de todos" (ICOMOS, 1994).

Asimismo, se debe resaltar que el patrimonio es una construcción social, un "artificio" ideado por alguien, en un momento y lugar dados, y con fines específicos, por lo que sus significados cambian según los criterios o intereses de cada época (Prats, 1997). De modo que las activaciones patrimoniales son procesos situados, es decir se dan en la complejidad del territorio y de las relaciones de poder existentes en él, cuestiones que definen y modelan los distintos procesos de apropiación del mismo (Haesbaert, 2005). En este contexto y, a fin de contribuir a generar una comprensión más amplia del patrimonio, capaz de abordar todas sus dimensiones y complejidad, en el presente trabajo se discute y reflexiona acerca de la dimensión pública del patrimonio desde una perspectiva histórico-dialéctica.

Este carácter público del patrimonio permite hacer un análisis más amplio de los procesos de patrimonialización de los bienes culturales en los cuales se generan dinámicas de apropiación y mercantilización de los mismos, muchas veces encubiertos. A través de estos verdaderos "procesos de expropiación", quienes adquieren el carácter de "dueños del patrimonio" gozan de derechos y asumen responsabilidades, lo que los equipara al estatus de carácter individual de los ciudadanos liberales (Galarza, 2016). Esta ciudadanía se funda en la presunción de que la igualdad es una "identidad cívica compartida" basada en "una abstracción del yo" (Lazar, 2013: 22-23). En este marco, se replica en el patrimonio el proceso de ciudadanía, en tanto categoría "incompleta" planteado por Sassen (Lazar, 2013), según el cual las condiciones del patrimonio que es excluido de esos parámetros definirán los términos de su posterior inclusión. Asimismo, el perfil de individuo masculino al que refiere la categoría de ciudadano (Lazar, 2013), se refleja en la relación que existe entre el concepto de patrimonio, y más concretamente de su prefijo 
patri-, con la palabra patriarcado, ya que ambas derivan del vocablo pater-que en latín significa padre- reforzando su estatus principalmente masculino.

$\mathrm{Al}$ indagar sobre los vocablos que se utilizan para denominar al conjunto de bienes culturales en otras lenguas, se observa que en el inglés (heritage) y en el alemán (erbe) se usan términos cuyos significados hacen referencia a la herencia. Sin embargo, en español no se usa "herencia" sino "patrimonio" que es un atributo del pater familias del derecho romano y refiere al conjunto de bienes que tiene el ciudadano romano y que, a su muerte, heredan sus hijos varones. De este modo, el patrimonio surge como una figura propia del derecho privado que recién en el siglo XIX, con el surgimiento del derecho público, pasa a ser también un atributo del Estado Nación (Endere, 2009).

Así, con la finalidad de crear un patrimonio nacional, las naciones surgidas en ese período llevaron a cabo diferentes procesos de apropiación/expropiación del patrimonio. Estos procesos se han dado, por un lado, sobre bienes que ya eran libremente apropiables o públicos o sobre bienes que pertenecían al ámbito privado y cuya intimidad y equilibrio el patrimonio viene a romper (1). Ejemplos de esto último puede ser el patrimonio inmaterial, así como bienes de propiedad privada individual que son expropiados por ciertos actores en razón de que, por su valor cultural, merecen ser conocidos y gozados por todos. En el caso de Argentina, un ejemplo elocuente de este proceso en sentido extremo lo constituye el patrimonio arqueológico y paleontológico que pasó a ser dominio público del Estado desde 1913. En estos procesos, y particularmente con la incorporación del patrimonio cultural inmaterial como nueva categoría, la herencia cultural de un individuo, grupo o comunidad se convierte en el "patrimonio de todos" (2). Es precisamente esa idea presupuesta de "interés común" la justificación por la cual este "debe" ser conservado y protegido por el Estado.

\section{Negatividades y positividades del patrimonio}

A fin de indagar sobre los efectos de los procesos de patrimonialización, resulta oportuno analizarlos a la luz de la dialéctica entre lo público popular y lo público aristocrático, siguiendo la comparación entre lo público de Bajtin (Gravano, 2017a) y lo público de Aristóteles (Gravano, 2017b). En este marco, puede afirmarse que el proceso de patrimonialización, es decir, la selección de bienes culturales que se efectúa con el fin de su salvaguarda, constituye un proceso de corte aristocrático, ya que se selecciona lo mejor -conforme a un criterio experto o de la elite- y se lo hace explícito, es decir, la positividad (3). Generalmente esta selección toma 
aquello que se destaca del conjunto de bienes culturales existentes, por ejemplo "el valor universal excepcional" que requiere la Convención de UNESCO de 1972 para nominar un sitio a la lista del Patrimonio Mundial o "el valor histórico o artístico" que debe justificarse en la ley de declaratoria de un bien para formar parte del patrimonio nacional (conforme a la Ley 12665 de Patrimonio Histórico y Artístico de la Nación). Por el contrario, la negatividad, en el sentido que lo plantea Gravano retomando a Lourau (1970), apunta al reverso de la "positividad", es decir a lo que se "hace sin decir que lo hace, o bien lo que (en realidad se) hace mientras hace lo que dice que hace" (Gravano, 2012: 6). Así, la principal negatividad del patrimonio estaría dada por el proceso de selección y eventual exclusión de bienes culturales que, a pesar de formar parte de las manifestaciones culturales de un pueblo, quedan fuera por la aplicación de criterios que están pensados para justificar la elección de ciertos bienes en detrimento de otros que quedan invisibilizados en el repertorio patrimonial, dejando de lado también a los actores sociales que los representan. Por ejemplo, a pesar del amplio espectro de bienes y manifestaciones que pueden ser consideradas patrimonio conforme a las definiciones antes desarrolladas, en la práctica declarar un bien como Patrimonio de la Humanidad o como Monumento, Lugar o Bien Histórico Nacional conlleva un largo proceso de nominación y el cumplimiento de múltiples requisitos, así como la evaluación de diferentes comités de expertos y, finalmente, una decisión política de aprobar la nominación en la Asamblea General de UNESCO o mediante una ley nacional. En este contexto, no son pocos los casos en que en estos procesos han pesado más las decisiones políticas que la valoración cultural de los bienes.

A pesar de esta distinción, se podría dividir al patrimonio en dos grandes grupos, atendiendo a los orígenes particulares de cada uno. Por un lado, se encuentra lo que aquí se denomina patrimonio formal, constituido por aquellos bienes patrimoniales existentes o patrimonializables acorde a las normativas de las instituciones oficiales. Por el otro, lo que se define en este trabajo como patrimonio autorreconocido, es decir, aquellos bienes que, aunque no cumplen con los requisitos actuales para ser considerados patrimonializables, son reconocidos y reivindicados por la propia comunidad como bienes valiosos. También podrían incluirse aquellas manifestaciones, prácticas y representaciones simbólicas que son valoradas por sus portadores (sean comunidades, grupos o individuos) como un verdadero legado cultural, pero que no son nombradas en términos de "patrimonio" y que si bien constituyen expresiones susceptibles de ser patrimonializadas, probablemente no sea ese el interés de sus portadores. A este patrimonio autorreconocido se lo considerará en adelante como público popular, en tanto incorpora a las personas que lo transmiten, rompiendo la barrera de actor/espectador. 
Dentro de esta clasificación se destaca el patrimonio inmaterial, que podría considerarse como lo público vivo (Gravano, 2017c), ya que se basa en las personas portadoras que transmiten una manifestación cultural. Respecto del patrimonio formal se lo considerará como lo público aristocrático, en tanto que el mismo representa "lo sagrado" y legitimado, es decir contiene características particulares que justifican su protección mediante mecanismos legales y administrativos que regulan su conservación, manejo y acceso del público.

Cabe destacar que la definición de lo que es considerado patrimonio ha variado significativamente a través del tiempo y se encuentra actualmente en constante expansión. A principios del siglo XX, la noción de patrimonio estaba esencialmente ligada a aquellos bienes que constituían íconos de la cultura occidental o estaban vinculados con los orígenes de la identidad nacional. A partir de los años '70s esa idea se fue transformando en "manejo de recursos culturales" (Endere, 2009), implicando un cambio conceptual hacia una noción amplia y dinámica del patrimonio que considera a todos los vestigios del pasado como potencialmente valiosos, aunque sujetos a procesos de evaluación, selección y gestión. Desde la década de 1990 se han incorporado nuevas categorías patrimoniales como paisajes culturales e itinerarios culturales (Conti, 2009), las cuales dan importancia tanto a los bienes culturales como a sus entornos y sus dimensiones inmateriales.

Esta tendencia de incorporar al patrimonio autorreconocido, es decir, lo público popular en los repertorios patrimoniales da lugar a un sinnúmero de interrogantes y, en especial, nos interpela sobre si este particular proceso de incorporación del patrimonio a la estética burguesa no le quita su sentido y significado, ya que el mismo deja de constituirse en una oposición a lo oficial, formal, es decir lo "sagrado" y "consagrado". Esta es precisamente la dialéctica de la contradicción y el conflicto, el juego de intereses que devela la negatividad. En este sentido, poner el foco de atención en las negatividades permite reflexionar sobre aquellas cuestiones que no son explicitadas en las justificaciones de por qué un bien merece ser protegido conforme a la normativa vigente a nivel nacional o internacional (es decir las positividades del mismo), pero que son gravitantes, ya que muchas veces permiten descubrir el verdadero sentido por el cual unos bienes son seleccionados en detrimentos de otros y de los grupos que los representan. Para ello es necesario indagar, en cada caso, los actores intervinientes, sus agendas y reales motivaciones, como se verá a continuación. 


\section{La dinámica social del patrimonio}

Acorde a las definiciones antes expuestas podemos afirmar que el patrimonio es la expresión creativa de un pueblo, es decir, al patrimonio lo definen los actores que se vinculan con él, produciéndolo, viviéndolo y por ende, siendo parte del mismo. En este sentido, a continuación se buscará develar algunas de las negatividades de los actores intervinientes en el patrimonio y relacionarlas con ejemplos.

Si bien son muchos los actores que intervienen en los procesos de patrimonialización, se los podría dividir a priori en cuatro grandes grupos de interés acorde a las acciones que realizan. Un primer grupo estaría constituido por los individuos, propietarios, colectivos u organizaciones sociales, es decir aquellos que están directamente involucrados con los bienes. En un segundo grupo, se agrupan las instituciones locales, nacionales o internacionales, las cuales pueden ser independientes o dependientes del Estado, y el Estado mismo representado en instituciones, especialmente aquellas vinculadas con el patrimonio, es decir, las que regulan o intervienen el patrimonio desde lo "oficial". El tercer grupo está representado por los ciudadanos y visitantes, que ven el patrimonio "desde afuera". Y, el último se integra por los profesionales o expertos que aplican sus conocimientos para investigar, conservar, proteger e interpretar el patrimonio.

Para cada grupo se podrían plantear ciertas negatividades, siendo necesario aclarar que se trata de una aproximación preliminar debido a que se requiere efectuar una investigación de campo más profunda para poder identificar, en cada caso, los grupos de interés involucrados, así como las hipotéticas negatividades, con mayor grado de profundidad.

Para el primer grupo de actores, la negatividad de patrimonializar ciertos bienes culturales podría consistir en resaltar ciertas representaciones simbólicas para que sirvan como instrumento de cohesión social y organización colectiva, así como de justificación y plataforma para viabilizar demandas no relacionadas particularmente con lo patrimonial. En este sentido, se ha señalado que el patrimonio tiene la potencialidad de representar simbólicamente una identidad y permite a las comunidades re-significarlo para generar un discurso de identidad que revalorice los valores locales (Prats, 1997). Un ejemplo interesante para analizar es el de las tejedoras pampeana de Azul (Pedrotta, Tancredi, Mariano y Endere, 2013) que, como tantos otros saberes, no se han divulgado y continúan siendo atesorados por sus poseedoras. En este caso se trata de mujeres descendientes directas y miembros de una comunidad indígena, quienes no solo reivindican estos conocimientos y técnicas como un legado cultural, sino que a través de su producción subyace y se mantiene un proceso de resistencia cultural que las define en tanto comunidad, mantienen vivo su saber y lo transmiten a sus descendientes 
mujeres según la tradición ancestral, en el marco de un proceso de reivindicación, lucha y resistencia al olvido.

El segundo grupo de actores, aquellos que regulan el patrimonio, ejercen una potestad en razón a su estatus institucional, que les permite elegir, disponer y ejercer el contralor o poder de policía sobre ciertos bienes. Desde esta posición oficial, también descrita como aristocrática, se justifican las acciones adoptadas sobre el patrimonio porque se actúa en representación "de todos y para todos", lo que los habilita para decidir qué es y qué no es importante proteger. Esta autoridad les permite también adoptar medidas extremas como la expropiación de los bienes naturales y culturales bajo la justificación del desarrollo económico, considerado una mejora para el bien común, pero cuya rentabilidad no vuelve a la comunidad de origen ni se refleja en una mejora de sus condiciones de vida. Sin embargo vale aclarar que existen casos en los que los procesos de patrimonialización tuvieron un impacto positivo en la vida de las comunidades locales (4). Cabe destacar además que ellos tienen la facultad de visibilizar un bien por sobre otro, en tanto el primero representa simbólicamente lo que se quiere mostrar 0 lo que se quiere ser. Otra negatividad podría ser la intención de controlar y regular los usos compatibles con la conservación del patrimonio, que implica en la práctica dejar afuera determinados actores sociales y su acceso a los bienes culturales. Asimismo, la patrimonialización o los procesos de renovación urbana se pueden utilizar para controlar el público que lo utiliza (Low, 2009), ya que, en el afán de proteger un bien cultural, se excluye a parte de la población. Un ejemplo de ellos ocurre con la puesta en valor de centros históricos que terminan generando gentrificación (entendida como procesos intensos de reestructuración y transformación urbana) o bien transformaciones urbanas de corte neoliberal que ocurren cuando se producen inversiones que encarecen el costo de vida y generan desplazamientos a otros sectores de la ciudad de la población que tradicionalmente era residente y usuaria de las áreas transformadas (Delgadillo Polanco, 2016).Todos estos ejemplos tienen en común enmascarar intenciones mercantilistas en los discursos que enarbolan el bien común y el goce público como justificación explícita de los procesos de patrimonialización.

El tercer grupo de actores identificados son aquellos que viven u observan al patrimonio desde el punto de vista del espectador, re-significan aquello que ven o experimentan y, en algunos casos, contribuye a reforzar su identidad. Sin embargo, muchas veces el acceso al patrimonio se da por una convención social, cuando en realidad no sienten que esos bienes o esas manifestaciones los representan o tienen un significado cultural para ellos. Por ejemplo, algunos habitantes de Olavarría consideran que la ceremonia del día de la Pachamama o el carnaval boliviano no sólo no los representa sino que lo ven como algo exótico sin comprender 
el significado que estas manifestaciones culturales poseen para algunos sectores populares y el aporte que implican a la diversidad cultural de la comunidad local en general (Mariano, 2011).

Por último, la negatividad del cuarto grupo identificado, es decir, los profesionales, puede observarse en la valoración que ellos hacen de ciertos patrimonios o de ciertos grupos de interés por sobre otros. Por ejemplo, la negatividad de algunos arqueólogos en desconocer la legitimidad de discursos alternativos sobre el patrimonio como la de los representantes de la denominada New Age en relación a la energía que poseen los sitios megalíticos (e.g. Parque de los Menhires in la provincia de Tucumán, Endere, 2007). Otro ejemplo puede ser las controversias en relación a incorporar en los inventarios del patrimonio arquitectónico bienes que poseen significación social y cultural para una comunidad o un grupo social pero cuya inclusión no puede justificar conforme a los criterios de autenticidad que establece la Carta de Venecia (ICOMOS,1964). Todos estos ejemplos dan cuenta de visiones contrapuestas sobre el patrimonio que rara vez son puestas de manifiesto en los textos de las declaratorias, aunque son parte de la arena de luchas.

\section{Territorialización del patrimonio}

Las relaciones que se constituyen y reproducen en torno del patrimonio están dispuestas en los espacios públicos y son vivenciadas por los diversos actores involucrados. Se entiende por espacios públicos aquellos donde se generan y existen conflictos y equilibrios, en los cuales las relaciones sociales se desarrollan y están en constante proceso de producción y coconstrucción (Galarza y Corte, 2016). Cada uno de los actores, a su vez y desde su lugar, interactúa, manteniendo el patrimonio vivo y ubicándolo en los espacios públicos. Estos constituyen algo más que el mero escenario donde se establecen y desarrollan esas relaciones, ya que son una parte misma del patrimonio. Al respecto cabe recordar lo señalado por Low en relación a los espacios públicos:

Los espacios de flujos son organizados sobre actividades de procesamiento de información, mientras que los espacios cotidianos se organizan sobre la lógica de tener una vida, proporcionar sustento y encontrar un lugar para vivir. La falta de conexión entre estos espacios y la falta de significado (5) resultante de los lugares cotidianos e instituciones políticas, son vivenciadas por las personas y resistidas a través de una variedad de 
estrategias individuales y colectivas. Las personas procuran reafirmar su identidad cultural, a menudo en términos territoriales, 'movilizándose para lograr sus demandas, organizar sus comunidades y singularizando sus espacios para preservar el significado, para reestablecer cualquier control limitado que puedan ejercer sobre sus trabajos y viviendas' (Castells, 1989: 350). Estos espacios que se identifican con los centros simbólicos de la vida social, fundamentales para la comunicación y la resistencia reales, son los espacios públicos (2009: 35-36).

En este contexto, el patrimonio y su apropiación social, en tanto reivindicación explícita de la identidad cultural territorializada por parte de determinados grupos, pueden ser consideradas como una particular manera de ejercer el derecho a la ciudad (Lefebvre, 1968; Harvey, 2008, 2013; Borja, 2012) y de visibilizar lo público vivo (Gravano, 2016), que se manifiesta en los espacios públicos (Borja, 2012). Cabe destacar que el derecho a la ciudad se define como la capacidad de una población de tener injerencia real sobre cómo es el lugar donde viven y los procesos que allí se dan. La defensa de este derecho es fundamental, ya que constituye "una respuesta democrática que integra a la vez derechos de los ciudadanos y los criterios urbanísticos que hacen posible su ejercicio" (Borja, 2012: 122).

Por su parte, la identidad cultural es un elemento dinámico, cambiante y permeable a factores externos, y el patrimonio está vinculado con ella y acompaña su dinamismo (Molano, 2007). Cabe destacar que las identidades, principalmente las de las clases subalternas, se ven altamente influenciadas por lo hegemónico (6), es decir el proceso por el cual se tiende a establecer lo que les corresponde ser o no ser a los demás grupos sociales. Sin embargo,

existe un margen de autonomía que proviene tanto de experiencias y observaciones de la realidad concreta como de la propia posición en la estructura social", siendo las identidades un "complejo resultado de un proceso histórico y de una formación social determinada (Guber, 1999: 179).

Gravano profundiza al respecto, al señalar que: "si hay cultura dominante es porque entre las ruinas de las reivindicaciones de la modernidad -entre ellas, el espacio público- actúa y revive lo popular-subalterno, aún en estado de "paciencia activa", que no deja de ser lucha" (2017c: 15). Cabe destacar que estas identidades culturales construyen el imaginario urbano a través de imágenes (Galarza y Corte, 2016).

Entender la reivindicación del patrimonio como parte del derecho a la ciudad es importante para incorporar aquellos sectores de la población cuyos imaginarios urbanos no coinciden con 
la estética hegemónica (7), y cuyo patrimonio se basa más en épicas barriales (Gravano, 2016) que en bienes materiales determinados. En este contexto, al reflexionar sobre el patrimonio cultural de las ciudades es importante poner el foco de análisis en el espacio público, ya que "es uno de los ámbitos sociales donde se pueden observar los procesos de cohesión social, de creación de identidad comunitaria, de solidaridad, de rituales y memoria colectiva, pero también es un ámbito donde se legitima el poder y la dominación, así como la resistencia y la lucha contra ese poder" (Monreal, 2016: 99). No obstante, es necesario considerar que el espacio urbano es "un escenario especialmente inestable, sostenido a base de acuerdos espontáneos, fruto en definitiva de una labor de producción colectiva y permanente" (Marrero Guillamón, 2008: 87). En ese marco, el patrimonio podría configurarse como un espacio de negociación, como arena de luchas (en términos de Gravano, 2016) en la cual se dirimen la imposición de unos sentidos sobre otros a través de mecanismos de hegemonía o dominación.

\section{Reflexiones finales}

En el presente se propone esbozar una mirada crítica sobre el patrimonio, poniendo especial énfasis en los contextos urbanos actuales. A lo largo del mismo se ha reflexionado sobre la multiplicidad de actores involucrados en los procesos de patrimonialización, así como aquellos silenciados o invisibilizados, poniendo en evidencia tanto la diversidad de sentidos y significados sobre el patrimonio, como las diferencias entre los grupos en términos de poder, legitimidad e intereses sobre el patrimonio. Rescatar estas diferencias y matices permite aproximarse a su complejidad e intentar encontrar un equilibrio entre las acciones, contribuyendo a generar políticas públicas que contemplen mecanismos de toma de decisiones más participativas. Paralelamente, se introduce el concepto del "derecho a la ciudad" a esta discusión, el que ha tomado fuerza en los últimos años debido a los procesos de transformación, segregación social y expulsión presentes en muchas ciudades. En este sentido, la identidad cultural y el patrimonio, debido a su capacidad para generar procesos de apropiación espacial, se establecen como cuestiones importantes a considerar a la hora de generar procesos de organización social que defiendan este derecho urbano fundamental. En ese marco recobra importancia la discusión sobre los espacios públicos, su uso y valoración comunitaria. No obstante, "Ios ciudadanos para poder usufructuar y/o apropiarse de dichos espacios (...) deben consumir las actividades artísticas o culturales que brinda, o bien de generarlas y producirlas" (Girola y Thomasz, 2013: 4). En este sentido, podría afirmarse que el 
patrimonio puede constituirse en un mecanismos para que las comunidades fortalezcan la identidad territorial y la cohesión social, ya que les permiten identificarse como un colectivo que lucha por mejorar sus condiciones de vida.

\section{Notas}

(1) Como Sennett (2011) señala, esto se podría incluir en el desequilibrio existente entre la vida privada y la vida pública, que conlleva a una "visión íntima de la sociedad", expresada en la pérdida del mundo impersonal y el desdibujamiento del límite del mundo de los sentimientos privados, que constituye un problema público de la sociedad contemporánea.

(2) Sobre este punto resulta interesante lo expresado por Lazar (2013: 25) cuando explica que "la noción de persona como un individuo portador de interés tiene mucho en común con las nociones de personas asumidas en las ideas occidentales de ciudadanía: es una visión "mercantilizada" de las personas (Strathern, 1988) como un individuo limitado que es dueño de una serie de derechos, responsabilidades e intereses".

(3) Como señala Gravano (2012) la positividad se entiende por cómo las organizaciones e instituciones se auto identifican, es decir, "lo que dicen (o se dice) que hacen".

(4) Un ejemplo reconocido es el de la Comunidad de Agua Blanca, en Ecuador, quienes al asumir el rol de "custodios del patrimonio arqueológico ancestral" lograron que se les permitiera seguir habitando en el Parque Nacional Machalilla. Actualmente viven de la actividad cultural y turística que generan de manera autónoma (Endere y Zulaica, 2015).

(5) Dicha falta de significado no es tal, sino que es un significado que expulsa a los verdaderos usuarios y genera una no-apropiación de parte de los mismos por ese espacio.

(6) Lo hegemónico es definido "como todo el proceso social vivido, organizado prácticamente por significados y valores específicos y dominantes" (Williams, 1997: 130), es decir que se constituye como "todo un cuerpo de prácticas y expectativas en relación con la totalidad de la vida: nuestros sentidos y dosis de energía, las percepciones definidas que tenemos de nosotros mismos y de nuestro mundo" (Williams, 1997: 131).

(7) Se entiende como estética hegemónica a aquellos modelos o imágenes del mundo que son tomadas como propias por estos sectores, aun cuando la misma es contraria a los intereses de esta clase.

\section{Bibliografía}

Borja, J. (2012). Revolución urbana y derechos ciudadanos: claves para interpretar las contradicciones de la ciudad actual. Barcelona: Departamento de Geografía Humana, Facultad de Geografía e Historia de la Universidad de Barcelona.

Conti, A. (2009). Nuevas categorías patrimoniales: del monumento histórico al territorio. Material de la Maestría en Gestión del Patrimonio de la Universidad Nacional de Mar 
del

Plata.

Recuperado

de

https://www.academia.edu/5855053/Nuevas_categor\%C3\%ADas_patrimoniales

Delgadillo Polanco, V. (2016). Patrimonio urbano de la Ciudad de México: la herencia disputada. Universidad autónoma de la Ciudad de México, México.

Endere, M. (2007). Management of archaeologicalsites and thepublic in Argentina. En BAR International Series 1708 (pp. 19-30). Oxford: Archaeopress.

Endere, M. (2009). Algunas Reflexiones acerca del Patrimonio. En Endere, M. y Prado, J. (ed.). Patrimonio, Ciencia y Comunidad. Su abordaje en los Partidos de Azul, Tandil y Olavarría (pp. 19-48). Olavarría: UNCPBA.

Endere, M. y Zulaica, L. (2015). Sustentabilidad Socio-Cultural y Buen Vivir en Sitios Patrimoniales: evaluación del Caso Agua Blanca, Ecuador. Ambiente \& Sociedade, 18(4), pp. 265-290.

Galarza, B (2016). La producción de lo público en el Oikos. En Grimberg, M. VIII Jornadas Santiago Wallace de Investigación en Antropología Social. Facultad de Filosofía y Letras, UBA, C.A.B.A.

Galarza, B. y Corte, V. (2016). El espacio público tatuado: murales por reclamos ambientales. En Gravano, A.; Silva, A. y Boggi, S. (Ed.). Ciudades vividas. Sistemas e imaginarios de ciudades medias bonaerenses (pp. 321-343). Buenos Aires: Editorial Café de las ciudades.

Girola, M. y Thomasz, A. (2013). Del "derecho a la vivienda" al "derecho a la cultura": reflexiones sobre la constitución del "derecho a la ciudad" en Buenos Aires desde una perspectiva etnográfica. Anuario antropológico, 2, pp. 131-163.

Gravano, A. (2012). Identidades y culturas organizacionales: algunas claves para la gestión social. Apunte de cátedra sobre identidades y culturas organizacionales, FACSO/UNICEN. Olavarría, Argentina.

Gravano, A. (2016). Épicas barriales: lo público-político vivo. Cuadernos de Antropología, 26(2), pp. 1-25.

Gravano, A. (2017a). Lo público popular. Manuscrito no publicado, Apunte de Cátedra, Seminario Antropología de lo Público, Maestría en Antropología Social, FACSO IUNICEN. Olavarría, Argentina.

Gravano, A. (2017b). Lo público aristocrático. Manuscrito no publicado, Apunte de Cátedra, Seminario Antropología de lo Público, Maestría en Antropología Social, FACSO/UNICEN, Olavarría, Argentina. 
Gravano, A. (2017c). Apuntes para una dialéctica de lo público. Manuscrito no publicado, Apunte de Cátedra, Seminario Antropología de lo Público, Maestría en Antropología Social, FACSO/UNICEN, Olavarría, Argentina.

Guber, R. (1999). Identidad social villera. En Boivin, M.; Rosato, A. y Arribas, V. (ed.). Constructores de Otredad. Una introducción a la Antropología Social y Cultural (pp. 178-192). Buenos Aires: Eudeba.

Haesbaert, R. (2005). Da desterritorializacao à multiterritorialidade. Anais do X Encontro de Geógrafos da América Latina. San Pablo: Universidad de San Pablo.

Harvey, D. (2008). El Derecho a la ciudad. New Left Review, 53, pp. 23-39.

Harvey, D. (2013). Ciudades rebeldes. Del derecho a la ciudad a la revolución urbana. Salamanca: Ediciones Akal.

International Council on Monuments and Sites (ICOMOS) (1964). Carta internacional sobre la conservación y la restauración de monumentos y sitios. Recuperado de https://www.icomos.org/charters/venice_sp.pdf

International Council on Monuments and Sites (ICOMOS) (1994). Documento de Nara en Autenticidad. Recuperado de https://bit.ly/2R0hXC9

Lazar, S. (2013). El Alto, ciudad rebelde. La Paz: Plural Ediciones.

Lefebvre, H. (1968). Ciudad y campo. En El derecho a la ciudad. Barcelona: Ediciones Península.

Lourau, R. (1970). El análisis institucional (traducción de N. Fiorito de Labrune). Buenos Aires: Amorrortu editores.

Low, S. (2009). Cerrando y reabriendo el espacio público en la ciudad latinoamericana. Cuadernos de Antropología Social, 30, pp. 17-38.

Mariano, M. (2011). Patrimonio intangible e identidad: representaciones bolivianas en Olavarría, Provincia de Buenos Aires, Argentina. Intersecciones en Antropología, pp. 155-166.

Marrero Guillamón, I. (2008). La producción del espacio público. Fundamentos teóricos y metodológicos para una etnografía de lo urbano. Contextos Revista d'antropologia $i$ investigació social, pp. 74-90.

Molano, O. (2007). Identidad cultural, un concepto que evoluciona. Revista Opera, 7, mayo, pp.69-84. Recuperado de http://www.redalyc.org/pdf/675/67500705.pdf

Monreal, P. (2016). Ciudades neoliberales: ¿el fin del espacio público? Una visión desde la antropología urbana. Quaderns-e, Institut Catalá d’Antropologia, 21(1), pp. 98-112. Recuperado de https://bit.ly/2EW2nB4 
Organización de las Naciones Unidas para la Educación, la Ciencia y la Cultura (UNESCO) (1972). Convención sobre la protección del patrimonio mundial, cultural y natural. Recuperado de https://bit.ly/1p81KRw

Organización de las Naciones Unidas para la Educación, la Ciencia y la Cultura (UNESCO) (1982). Conferencia Mundial de la UNESCO sobre el Patrimonio Cultural, México.

Pedrotta, V.; Tancredi, M.; Mariano, M. y Endere, M. (2013). Tejiendo saberes. Patrimonio intangible, identidad y valorización social: el caso de Ercilia Cestac. Revista Runa. Archivo para las ciencias del hombre, 1(34), pp. 91-112.

Prats, L. (1997). Antropología y Patrimonio. Barcelona: Editorial Ariel.

Sennett, R. (2011). El declive del hombre público. Barcelona: Anagrama.

Williams, R. (1997). Marxismo y literatura. Barcelona: Ediciones Península. 